\title{
Chemiluminescent ELISA for the BTEX Determination in Water and Soil
}

\author{
Elisabetta MAIOLINI,* Dietmar KNOPP,** Reinhard NiESSNER, ** Sergei EREMIN,*** \\ Luca BolELLI,* Elida Nora FERRI,* and Stefano GIROTTI*ं \\ *Dipartimento di Scienza dei Metalli, Elettrochimica e Tecniche Chimiche, Università di Bologna, \\ Via S. Donato 15, 40127 Bologna, Italy \\ **Institute of Hydrochemistry and Chemical Balneology, Technische Universität München, \\ 81377 München, Germany \\ ***Department of Chemical Enzymology, Faculty of Chemistry, M. V. Lomonosov Moscow State University, \\ Moscow 119899, Russia
}

\begin{abstract}
An indirect competitive chemiluminescence enzyme-linked immunosorbent assay (CL-ELISA) for the determination of benzene, toluene, ethylbenzene, and ortho-, meta-, para-xylenes (BTEX) in soil and water was developed. The assay was optimized concerning the coating conjugate concentration, anti-BTEX antiserum dilution, incubation time effect on primary and secondary antibody incubation, and temperature effect on the competitive step and tolerance to different organic solvents. The $\mathrm{IC}_{50}$ and lower limit of the detection $\left(\mathrm{LDD}_{90}\right)$ values were 4.6 and $0.5 \mu \mathrm{g} \mathrm{mL}^{-1}$, respectively. While water samples could be analyzed directly, soil has to be extracted and diluted prior to immunochemical measurements. BTEX could be recovered from spiked soil with a yield higher than $60 \%$ using 5-min ultrasonication with methanol. Finally, the assay was applied to soil and water samples collected at a contaminated site in Italy, and was compared to GC-MS.
\end{abstract}

(Received March 4, 2010; Accepted May 7, 2010; Published July 10, 2010)

\section{Introduction}

Benzene, toluene, ethylbenzene and ortho-, meta-, para-xylenes (BTEX) are volatile organic components of petroleum and its derivates, such as gasoline and diesel fuel. They are used as solvents for many purposes, ${ }^{1}$ and because of their relative solubility in water they can contaminate the soil and groundwater, and thus provoking environmental pollution. In the last years their toxicity and carcinogenetic effects, in the case of benzene, have become a serious concern for human health. ${ }^{2}$ The admitted limits for benzene in drinking water are set at 5 and $1 \mu \mathrm{g} \mathrm{L}^{-1}$ in United States and European Union, respectively.,4 After the accidental contamination of soil and water, the BTEX concentrations are generally several orders of magnitude higher. Several methods are used for BTEX determination and the choice among the various extraction, separation and detection techniques also depends on the matrix to be analyzed. ${ }^{5}$ In water and soil the most commonly employed methods are based on solid-phase microextraction (SPME) coupled to gas chromatography-mass spectrometry (GC-MS), ${ }^{6-8}$ or to a gas chromatography-flame ionization detector (GC-FID). ${ }^{9-11}$ BTEX determination using gas chromatography is quite time consuming, and needs special instrumentation, and thus the development of alternative methods that could be used even on-site is highly required..$^{5,12,13}$

$\dagger$ To whom correspondence should be addressed.

E-mail: stefano.girotti@unibo.it
Immunochemical assays represent simple, rapid and low-cost methods, often allowing examining samples without extensive pretreatment. ${ }^{14}$ Immunological methods reported for BTEX are mainly ELISAs, ${ }^{15,16}$ and also fluorescence polarization immunoassay. ${ }^{17}$ So far, assays based on chemiluminescent detection were not reported, although they have been shown to be less interference-prone and more sensitive than the conventional colorimetric method. ${ }^{18}$

The aim of the present work was to develop an indirect competitive chemiluminescent enzyme-linked immunosorbent assay (CL-ELISA) for BTEX using the same antiserum that proved to be optimal for ELISA development. ${ }^{14,15}$ In contrast to this earlier reported assay, new coating antigens were synthesized based on different phenyl-alkanoic acids and bovine serum albumin (BSA) and ovalbumin (OVA) as carrier proteins. Related to the high volatility of target analytes, considerable efforts were devoted to verify the estimated optimal ELISA conditions, such as the temperature and incubation time, as well as the addition of an organic co-solvent. In excess of water samples, the application of CL-ELISA to soil monitoring was at the focal point of the presented investigation.

\section{Experimental}

Reagents and chemicals

All reagents were of analytical grade. Benzene, toluene, ethylbenzene and $o-, m-, p$-xylenes were from Sigma Aldrich (Steinheim, Germany) and goat anti-rabbit IgG-horseradish 
peroxidase (IgG-HRP) was purchased from DakoCytomation (Glostrup, Denmark). The primary anti-BTEX polyclonal antibody was prepared as described earlier. ${ }^{15}$ Five haptens were synthesised from phenol- $\left(\mathrm{CH}_{2}\right)_{\mathrm{n}}-\mathrm{COOH}$, and were all conjugated to the proteins ovalbumin (OVA), with the exception of BTEX-4; also to bovine serum albumin (BSA), as described. ${ }^{17}$

The $0.05 \mathrm{M}$ carbonate-bicarbonate buffer (CBB), pH 9.6 (15 mM Na $2 \mathrm{CO}_{3}, 30 \mathrm{mM} \mathrm{NaHCO}$ ), $10 \mathrm{mM}$ phosphate buffer (PBS), pH 7.4 (137 mM NaCl, $2.7 \mathrm{mM} \mathrm{KCl,} 10 \mathrm{mM} \mathrm{Na}_{2} \mathrm{HPO}_{4}$, $2 \mathrm{mM} \mathrm{KH} \mathrm{KO}_{4}$ ), $1 \mathrm{mM}$ PBS-Tween 20 (PBST) (10 mM PBS, $0.05 \%$ Tween 20), PBS-gelatine $1 \mathrm{X}$ (PBSG 1X) (1 mM PBS, $0.5 \%$ fish gelatine), PBS-gelatine $2 \mathrm{X}$ (PBSG 2X) (2 mM PBS, $1 \%$ fish gelatine) and $0.2 \mathrm{M}$ borate buffer (BB), pH $8.5(50 \mathrm{mM}$ $\mathrm{Na}_{2} \mathrm{~B}_{4} \mathrm{O}_{7} \cdot 10 \mathrm{H}_{2} \mathrm{O}, 200 \mathrm{mM} \mathrm{H} \mathrm{BO}_{3}$ ) were employed.

The chemiluminescent mixture, prepared in $0.2 \mathrm{M} \mathrm{BB}, \mathrm{pH} 8.5$ contained: $1 \mathrm{mM}$ luminol, $0.5 \mathrm{mM}$-iodophenol (both from Sigma, Germany) and $1 \mathrm{mM}$ hydrogen peroxide (Merck, Germany).

\section{Soil and water samples}

Soil samples were collected at different sites and at different depths in the area, suspected to be contaminated by hydrocarbon spills of an Italian chemical factory now out of use. The first group included samples A1 (depth $0 \mathrm{~m}$ ), A2 (depth 7 - $8 \mathrm{~m}$ ), A3 (depth $11-12 \mathrm{~m}$ ) and B (depth $10-11 \mathrm{~m}$ ). Three months later samples S1 (depth $1-2 \mathrm{~m}$ ), S2 (depth $2-7 \mathrm{~m}$ ), and S3 (depth $12-13 \mathrm{~m}$ ) were collected. Water samples (W1, W2, and W3) were collected in wells and drilling points in the polluted area at the same time of A and B soil samples. All water samples presented an oily fraction on the water fraction, and only the water fractions were analyzed without any pretreatment.

\section{Extraction of soil samples}

The soil samples were extracted by putting $2 \mathrm{~g}$ of soil into $5 \mathrm{~mL}$ of methanol and following two different procedures. "S" extraction: the sample was shaken for $30 \mathrm{~min}$ on an MTS2 shaker (IKA Labortechnik, Staufen, Germany) and centrifuged $10 \mathrm{~min}$ at $2000 \mathrm{~g}$ in an ALC centrifuge Model 4222 (ALC International, Cologno Monzese, Milano, Italy). "SS" extraction: the samples were treated for 5 min with ultrasound (138 W average absorbed power, $28-34 \mathrm{kHz}$ frequency, Starsonic 60, Liarre s.r.l., Bologna, Italy) and then centrifuged as described above. The supernatant was stored in a refrigerator until use.

\section{Spiked samples}

In order to estimate the influence both of the matrix and the extraction method on the recovery value, the blank soils and blank soil extracts were spiked with BTEX standard solutions. A standard stock solution was prepared by mixing equivalent volumes of individual standard solutions $\left(10 \mathrm{~g} \mathrm{~L}^{-1}\right.$ in methanol $)$ of each of the six standards: benzene, toluene, ethylbenzene and $o-, m-$, and $p$-xylenes. The working solutions for spiking were obtained by the dilution in methanol of the standard stock solution; $1 \mathrm{~mL}$ of blank soil extract was spiked with the working solution to obtain a final concentration of 5,15 , and $30 \mu \mathrm{g} \mathrm{mL}^{-1}$, whereas $2 \mathrm{~g}$ of blank soils were spiked to obtain samples with contents of 10, 20 and $50 \mu \mathrm{g} \mathrm{g}^{-1}$ of BTEX. After spiking, the soil was left at room temperature for $1 \mathrm{~h}$ before extraction.

\section{Indirect competitive chemiluminescence ELISA (CL-ELISA)}

Indirect competitive ELISA (Fig. 1) was carried out in 96-well microtiter plates $\left(\right.$ Costar $^{\circledR}$ assay plate, high binding, flat bottom, Corning Inc., NY) that were coated with hapten conjugates in a concentration range of $0.5-2.0 \mu \mathrm{g} \mathrm{mL}^{-1}$, by using $0.05 \mathrm{M}$

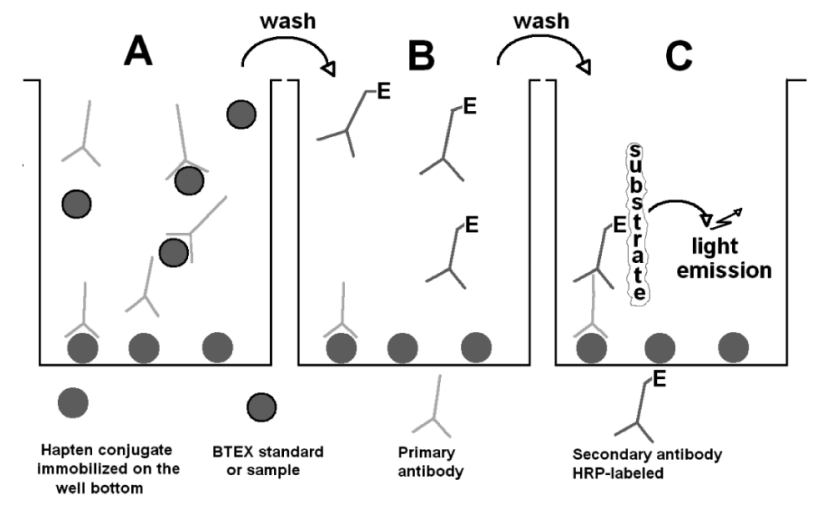

Fig. 1 Schematic drawing of the indirect CL-ELISA format (HRP, horseradish peroxidase). A, Coating with coating-antigen and the addition of a standard/sample and anti-analyte antibody; B, addition of a secondary enzyme-labelled antibody (HRP); C, addition of an enzyme substrate (luminol/ $\mathrm{H}_{2} \mathrm{O}_{2}$ ).

$\mathrm{CBB}, \mathrm{pH} 9.6(100 \mu \mathrm{L} /$ well $)$. After incubating overnight at $4^{\circ} \mathrm{C}$, the plates were washed (Wellwash 4, Labsystem, Sweden) 3 times with $200 \mu \mathrm{L}$ of PBS; the uncoated sites were blocked by adding $200 \mu \mathrm{L} /$ well of PBSG $1 \mathrm{X}$ and by incubating at $37^{\circ} \mathrm{C}$ for $30 \mathrm{~min}$, with shaking. After washing, $50 \mu \mathrm{L} /$ well of antiserum dilution, in the range from $1 / 1000$ to $1 / 3000$ in PBSG $2 X$, and $50 \mu \mathrm{L} /$ well of standard solutions or sample extracts were added and incubated for $30 \mathrm{~h}$ at $4{ }^{\circ} \mathrm{C}$. After washing, $100 \mu \mathrm{L} /$ well of goat anti-rabbit IgG-HRP diluted 1:2000 in PBSG 1X (according to the manufacturer guidelines) was added, and the plate was further incubated for $90 \mathrm{~min}$ at RT. After a final wash, $100 \mu \mathrm{L}$ of the substrate solution was added to each well, and the luminescence was measured by a Victor 1420 Multilabel Counter (Wallac-Perkin Elmer, Waltham, MA).

For each of the nine BTEX-protein conjugates the optimal combination of its coating concentration and the anti-BTEX antiserum dilution was determined by checkerboard titration. The effects on the performance of the immunoassay of the organic solvents methanol $(\mathrm{MeOH})$, acetonitrile $(\mathrm{ACN})$, and dimethyl sulfoxide (DMSO) at final concentrations of 1,5 , and $10 \%$ and the effects of the temperature and incubation time on the competitive incubation step were evaluated.

The chemiluminescence data, expressed as relative luminescent units (RLU), were normalized according to the following expression: $\% B / B_{0}=100\left(A-A_{\text {excess }}\right) /\left(A_{0}-A_{\text {excess }}\right)$, and then mathematically fitted to a four-parameter logistic equation using the Sigmaplot ${ }^{\circledR}$ software (SPSS) Ver. 8.0, as already described. ${ }^{19}$

\section{Gas chromatographic analyses}

The BTEX content in soil and water samples extracted with dichloromethane was determined by gas chromatography-mass spectrometry (GC-MS) (HP Agilent 6890N GC gas chromatograph-5973N mass spectrometer, Santa Clara, CA) according to the U.S.-EPA methods $5021 \mathrm{~A}^{20}$ and EPA 8260C. ${ }^{21}$

\section{Results and Discussion}

\section{Optimization of the CL-ELISA protocol}

The optimal proportions of the immunoreagents obtained by testing different concentrations of coating antigen and antiserum are summarized in Table 1.

Concerning the effect of organic solvents, each conjugate was tested by means of the indirect competitive immunoassay. 
Table 1 Optimal concentrations of immunoreagents

\begin{tabular}{ccc}
\hline Coating conjugate $^{\mathrm{a}}$ & $\begin{array}{c}\text { Coating conjugate } \\
\text { concentration/ } \mu \mathrm{g} \mathrm{mL}^{-1}\end{array}$ & $\begin{array}{c}\text { Anti-BTEX } \\
\text { antiserum dilution }\end{array}$ \\
\hline BTEX-1-BSA & 1 & $1 / 2000$ \\
BTEX-2-BSA & 1 & $1 / 2000$ \\
BTEX-3-BSA & 0.5 & $1 / 2500$ \\
BTEX-5-BSA & 0.2 & $1 / 2500$ \\
BTEX-1-OVA & 1 & $1 / 2000$ \\
BTEX-2-OVA & 1 & $1 / 2000$ \\
BTEX-3-OVA & 0.5 & $1 / 2500$ \\
BTEX-4-OVA & 0.1 & $1 / 2000$ \\
BTEX-5-OVA & 0.1 & $1 / 2000$ \\
\hline
\end{tabular}

a. Structures of BTEX haptens.

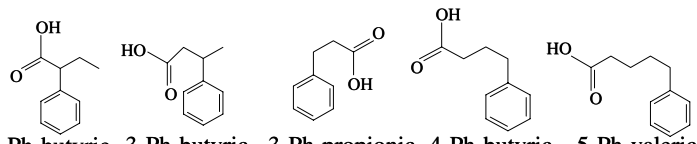

2-Ph-butyric 3-Ph-butyric 3-Ph-propionic 4-Ph-butyric 5-Ph-valeric acid BTEX-1 acid BTEX-2 acid BTEX-3 acid BTEX-4 acid BTEX-5

For this investigation, a blank sample without the addition of any BTEX standard solution was tested. By using various conjugates, the changes observed in light emission were generally minimal, as shown for the BTEX-1-BSA conjugate in Fig. 2. While a small increase of the light emission was recorded by using methanol or ACN, a small decrease after the addition of $10 \%$ DMSO was found.

On the contrary, by using the BTEX-1-OVA conjugate, a completely different behavior was observed (Fig. 3). Independently from the solvent, a continuous and significant decrease in the light emission was noticed with increasing solvent concentration. This effect was most pronounced for DMSO addition. Based on these findings, it was decided to use methanol at a final concentration of 5\% in all assays with the exception of those assays employing the BTEX-1-OVA conjugate, which were carried out with $1 \%$ of methanol.

When analyzing BTEX, the difficulty created by their extreme volatility must be considered. Particularly when the assay is performed in containers with a great surface-to-volume ratio, like in the case of microplate wells. First of all, the influence of the temperature on assay sensitivity was investigated carrying out the various steps of the assay both at room temperature and at $4^{\circ} \mathrm{C}$. While preparing the standard curve solutions and their deposition into the microplate wells, the test tubes and the plate were kept in iced water $\left(\sim 4^{\circ} \mathrm{C}\right)$ or at room temperature. The competitive step was performed while leaving the microplate inside the fridge, or at room temperature.

Further, with the aim to minimize the loss of analytes, we tested the effect of using a sealing sheet on the plate (Microtiter Sealing Plate, Sigma-Aldrich) during the competitive step and the luminescence measurement. In the latter case, basically to reduce the atmospheric influence on the background signal of luminol-based chemiluminescence assays. ${ }^{22}$

Concerning the competitive step, the best results were obtained at $4^{\circ} \mathrm{C}$ and without a sealing sheet on the plate, confirming the findings of Beyer et al. ${ }^{14,15}$ At room temperature the sensitivity of the assay decreased drastically, making it sometimes impossible even to obtain an acceptable calibration curve. When sealing the plates during the luminescence measurement, a decrease from 11 to $9 \%$ of the coefficient of variation $(\mathrm{CV})$ was observed. Although the reduction of the imprecision of the assay was not as high as reported by Towbin, ${ }^{22}$ its favorable use was convincing.

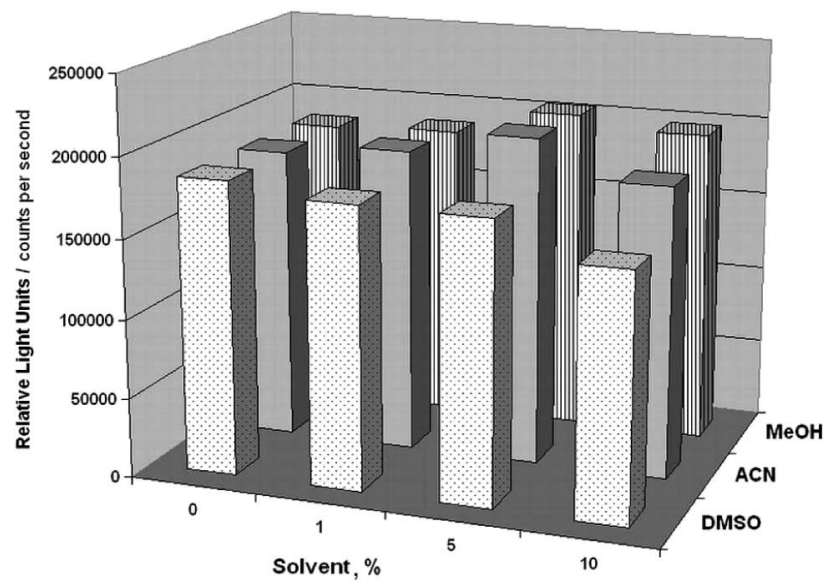

Fig. 2 Effect of the methanol $(\mathrm{MeOH})$, acetonitrile $(\mathrm{ACN})$ and dimethyl sulfoxide (DMSO) concentrations on the luminescence signal using BTEX-1-BSA as a coating conjugate.

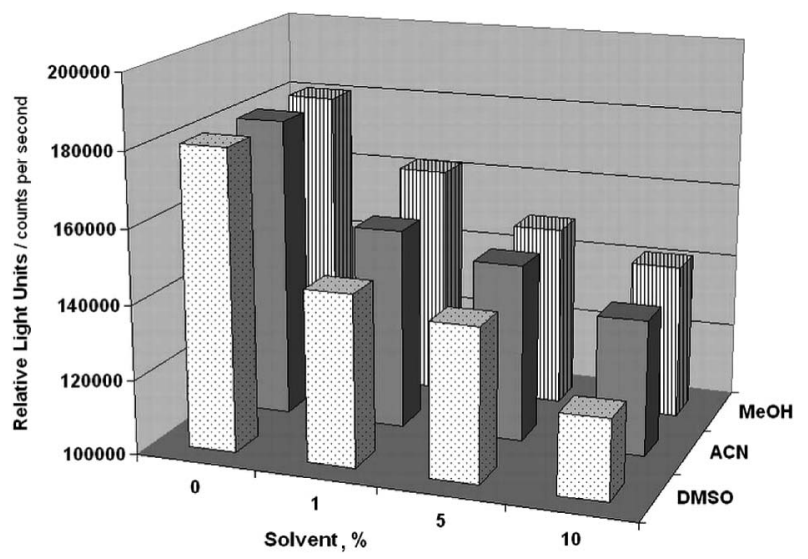

Fig. 3 Effect of $\mathrm{MeOH}, \mathrm{ACN}$ and DMSO concentrations on the luminescence signal using BTEX-1-OVA as a coating conjugate.

In order to study the effect of time on the competitive and secondary antibody incubation steps, periods of 15, 30, 60 and 90 min were tested. The highest sensitivity was reached with 30 min of incubation without any shaking for the primary antibody, whereas a longer time of 90 min with shaking proved to be optimal for the incubation of the secondary antibody.

\section{Calibration curve}

Under these conditions, useful competition curves only by using BTEX-5-BSA coating conjugates were obtained (Fig. 4).

Upon using any of the other conjugates, the competition curves were unusable. The optimal concentration of the haptenconjugate and antiserum dilution used were $0.2 \mu \mathrm{g} \mathrm{mL}^{-1}$ and 1:2500 for BTEX-5-BSA and $1 \mu \mathrm{g} \mathrm{mL}^{-1}$ and $1: 2000$ for BTEX-1-BSA, respectively. The $\mathrm{IC}_{50}$ and the least-detectable dose $\left(\mathrm{LDD}_{90}\right)$ values were estimated at 4.56 and $0.50 \mu \mathrm{g} \mathrm{mL}^{-1}$ for BTEX-5-BSA and 0.12 and $0.01 \mu \mathrm{g} \mathrm{mL}^{-1}$ for BTEX-1-BSA, respectively. The $\mathrm{LDD}_{90}$ was defined as the lowest BTEX concentration exhibiting a $90 \%$ mean luminescence intensity of the zero standard. The competition curves obtained by using the other prepared conjugates showed $\mathrm{IC}_{50}$ values higher than $50 \mu \mathrm{g} \mathrm{mL}^{-1}$, making them unsuitable for analyses.

The repeatability (precision), expressed as the coefficient of 


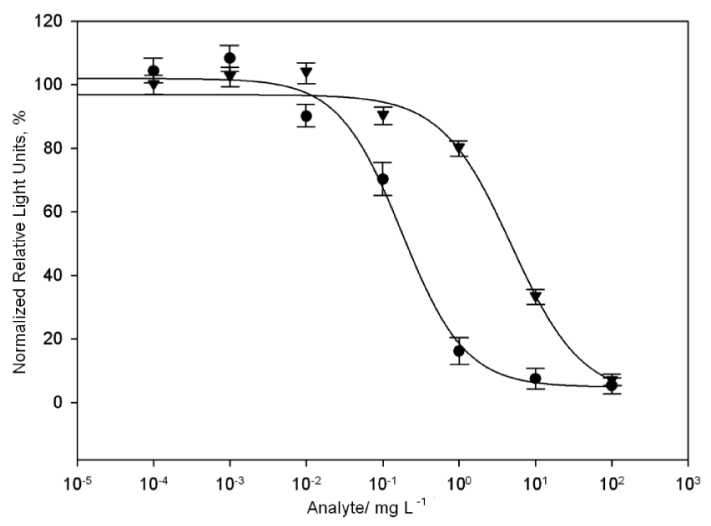

Fig. 4 Calibration curves obtained by using different coating conjugates and the BTEX standard solution prepared in methanol:water $(5: 95, \mathrm{v} / \mathrm{v})$. •, BTEX-1-BSA; $\mathbf{v}, \mathrm{BTEX}-5$-BSA. Error bars, \pm standard deviation $(n=3)$.

Table $2 \mathrm{IC}_{50}$ and $\mathrm{LDD}_{90}$ values for the individual components of the BTEX mixture obtained by using BTEX-1-BSA or BTEX-5-BSA as coating conjugates at a concentration of 1 and $0.2 \mu \mathrm{g} \mathrm{mL}-1$, respectively

\begin{tabular}{|c|c|c|c|c|}
\hline \multirow[b]{2}{*}{ Analyte } & \multicolumn{2}{|c|}{ BTEX-5-BSA conjugate } & \multicolumn{2}{|c|}{ BTEX-1-BSA conjugate } \\
\hline & $\begin{array}{c}\mathrm{IC}_{50} / \\
\mu \mathrm{g} \mathrm{mL}^{-1}\end{array}$ & $\begin{array}{c}\mathrm{LDD}_{90} / \\
\mu \mathrm{g} \mathrm{mL}^{-1}\end{array}$ & $\begin{array}{c}\mathrm{IC}_{50} / \\
\mu \mathrm{g} \mathrm{mL}^{-1}\end{array}$ & $\begin{array}{c}\mathrm{LDD}_{90} / \\
\mu \mathrm{g} \mathrm{mL}^{-1}\end{array}$ \\
\hline Benzene & 0.03 & 0.002 & 0.31 & 0.010 \\
\hline Ethylbenzene & 1.65 & 0.102 & 0.70 & 0.036 \\
\hline Toluene & 0.97 & 0.019 & 0.88 & 0.051 \\
\hline$o-, m$-, $p$-Xylene & 0.06 & 0.003 & 0.02 & 0.005 \\
\hline
\end{tabular}

variation (CV), was $20 \%$ for 1 -BSA and $9 \%$ for 5 -BSA.

The two above-mentioned coating conjugates were used for testing the antiserum specificity for each single component of the BTEX mixture. The antiserum showed higher affinity for benzene and xylene(s) than for toluene and ethylbenzene, as reported in Table 2.

The BTEX-1-BSA conjugate showed higher sensitivity, but lower reproducibility, compared with BTEX-5-BSA, and thus we decided to use the latter for the soil and water sample analyses.

Calibration curves were established with spiked extracts of blank soil samples obtained both by the "S" and "SS" extraction procedures (Fig. 5). The $\mathrm{IC}_{50}$ and $\mathrm{LDD}_{90}$ values were 3.7 and $0.3 \mu \mathrm{g} \mathrm{mL} \mathrm{L}^{-1}$ for the "S" extract and 2.1 and $0.2 \mu \mathrm{g} \mathrm{mL} \mathrm{m}^{-1}$ for the "SS" extract. These values were comparable to those obtained for the BTEX calibration curve in water/methanol, indicating negligible interferences of the matrix on the assay.

By comparing CL-ELISA data obtained with spiked blank soil "S" and "SS" extracts, higher recovery rates and higher precision were observed for the "SS" extracts, i.e., samples that were prepared by ultrasonication (Table 3).

\section{Analyses of real samples}

The soil samples $(n=7)$ were extracted by using the SS extraction method, whereas the water samples $(n=3)$ did not need any extraction procedure. With the exception of sample S1, which did not show contamination by both GC-MS and CL-ELISA analysis, all soil samples were identified as being positive, i.e., were contaminated by BTEX. No false positive or

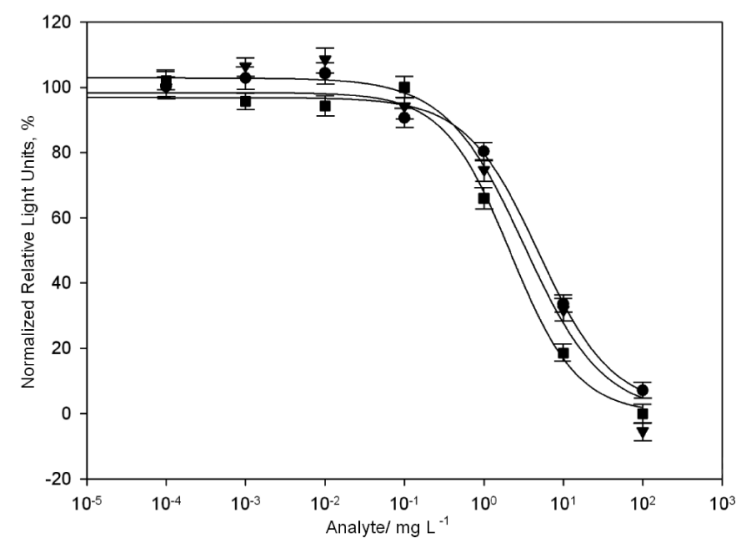

Fig. 5 BTEX standard calibration curves prepared in methanol:water (5:95, v/v), " "SS" extract and - "S" extract, using BTEX-5-BSA as conjugate. Error bars, \pm standard deviation $(n=3)$.

Table 3 (A) Matrix effect of the two kind of blank soil extracts ("S" and "SS") on the measurement of added standard BTEX solution, (B) recovery values of BTEX spiked to blank soils obtained on "S" and "SS" extracts

\begin{tabular}{|c|c|c|c|c|}
\hline \multicolumn{5}{|c|}{ (A) Blank soil extracts spiked with BTEX standard solution } \\
\hline $\begin{array}{l}\text { BTEX amount } \\
\text { added } / \mu \mathrm{g} \mathrm{mL}^{-1}\end{array}$ & $\begin{array}{c}\text { Soil } \\
\text { extract }\end{array}$ & $\begin{array}{c}\text { BTEX amount } \\
\text { measured/ } \mathrm{g} \mathrm{mL}^{-1}\end{array}$ & $\begin{array}{c}\mathrm{CV} \\
\%\end{array}$ & $\begin{array}{c}\text { Mean } \\
\text { recovery, \% }\end{array}$ \\
\hline \multirow[t]{2}{*}{5} & S & 2.1 & 13.3 & 42.0 \\
\hline & SS & 3.3 & 11.1 & 66.2 \\
\hline \multirow[t]{2}{*}{15} & $\mathrm{~S}$ & 8.8 & 12.1 & 58.7 \\
\hline & SS & 12.3 & 10.3 & 82.3 \\
\hline \multirow[t]{2}{*}{30} & $\mathrm{~S}$ & 21.9 & 7.2 & 73.0 \\
\hline & SS & 25.2 & 6.4 & 83.7 \\
\hline \multicolumn{5}{|c|}{ (B) Blank soil samples spiked with BTEX standard solution } \\
\hline $\begin{array}{l}\text { BTEX amount } \\
\text { added/ } \mu \mathrm{g} \mathrm{g}^{-1}\end{array}$ & $\begin{array}{l}\text { Extraction } \\
\text { method }\end{array}$ & $\begin{array}{l}\text { BTEX amount } \\
\text { measured/ } \mu \mathrm{g} \mathrm{g}^{-1}\end{array}$ & $\begin{array}{c}\mathrm{CV} \\
\%\end{array}$ & $\begin{array}{c}\text { Mean } \\
\text { recovery, \% }\end{array}$ \\
\hline \multirow[t]{2}{*}{10} & $\mathrm{~S}$ & 3.1 & 19.3 & 31.0 \\
\hline & SS & 6.6 & 16.8 & 66.2 \\
\hline \multirow[t]{2}{*}{20} & $S$ & 7.8 & 13.3 & 38.9 \\
\hline & SS & 14.4 & 11.5 & 72.1 \\
\hline \multirow[t]{2}{*}{50} & $\mathrm{~S}$ & 21.5 & 19.1 & 43.0 \\
\hline & SS & 38.9 & 15.8 & 77.8 \\
\hline
\end{tabular}

false negative results were obtained by the immunoassay. A clear decrease of BTEX contamination was observed in parallel with the depth (Table 4). Exactly the same behavior was found with both analytical techniques. Compared with soil samples, all analyzed water samples were polluted in a significantly higher amount. Importantly, the concentrations determined by CL-ELISA were underestimated by a factor of about two compared to GC-MS. This is not surprising if the cross-reactivity of the used antiserum with the individual BTEX analytes is considered.

\section{Conclusion}

In this work the performance of nine hapten-protein conjugates and other assay parameters for the development of a CL-ELISA for the determination of BTEX were evaluated and optimized. The indirect competitive CL-ELISA was proven to be applicable to water samples and soil extracts from a contaminated site. As previously reported, the immunological analysis of small and 
Table 4 Comparison between CL-ELISA and the GC-MS determination of the BTEX content in real water and soil ("SS" extracts) samples $(n=7)$

\begin{tabular}{|c|c|c|c|c|}
\hline \multirow[b]{2}{*}{ Sample } & \multicolumn{2}{|c|}{ CL-ELISA } & \multicolumn{2}{|c|}{ GC-MS } \\
\hline & $\begin{array}{l}\text { BTEX } \\
\text { content/ } \\
\mu \mathrm{g} \mathrm{mL} L^{-1}\end{array}$ & $\begin{array}{c}\text { Repeatability } \\
\text { CV, } \%\end{array}$ & $\begin{array}{c}\text { BTEX } \\
\text { content/ } \\
\mu \mathrm{g} \mathrm{mL}^{-1}\end{array}$ & $\begin{array}{c}\text { Repeatability } \\
\text { CV, \% }\end{array}$ \\
\hline Soil: A1 (0 m) & 13.6 & 1.8 & 25.2 & 3.6 \\
\hline Soil: A2 (7 - 8 m) & 6.9 & 3.1 & 15.4 & 2.9 \\
\hline $\begin{array}{l}\text { Soil: A3 } \\
\qquad(11-12 \mathrm{~m})\end{array}$ & 3.4 & 2.6 & 7.6 & 4.3 \\
\hline $\begin{array}{l}\text { Soil: B } \\
\qquad(10-11 \mathrm{~m})\end{array}$ & 12.4 & 1.3 & 27.4 & 5.3 \\
\hline Soil: S1 (1 - 2 m) & ND & - & ND & - \\
\hline Soil: S2 (2 - 7 m) & 9.8 & 2.3 & 18.5 & 3.1 \\
\hline $\begin{array}{l}\text { Soil: S3 } \\
(12-13 \mathrm{~m})\end{array}$ & 7.5 & 2.4 & 15.4 & 3.7 \\
\hline Water: W1 & 197 & 16 & 467 & 20 \\
\hline Water: W2 & 308 & 15 & 585 & 12 \\
\hline Water: W3 & 397 & 11 & 595 & 15 \\
\hline
\end{tabular}

Soil samples: each depth is indicated in parentheses.

volatile analytes, such as BTEX, is challenging. A temperature of $4{ }^{\circ} \mathrm{C}$ and an incubation time of $30 \mathrm{~min}$, without sealing the microtiter plate, for the competitive step were found to be optimal. By using the same antiserum and different coating conjugates, very similar $\mathrm{IC}_{50}$ and $\mathrm{LDD}_{90}$ values of 4.6 and $0.5 \mu \mathrm{g} \mathrm{mL}^{-1}$, respectively, compared to the reported BTEX-ELISA were obtained. ${ }^{14,15}$ For this immunoassay, as for each class-specific ELISA, underestimated concentrations will be obtained when unknown samples will be measured, which is caused by the target analyte distribution and corresponding antibody affinity. This limitation can be overcome by site-specific calibration. In detail, the target analyte partition of a few random samples from the contaminated site should be determined by a reference method as the base for the calibration of the CL-ELISA with known cross-reactivities of the single compound.

\section{Acknowledgements}

This work was supported from the University of Bologna (RFO, Focused Fundamental Research Projects) and Grant 08-03-97047 of Russian Foundation for Basic Research "Development of Condensation Preconcentration for Sensitive and Rapid Detection of Toxicants in Air by Immunochemical and Gas Chromatography-Mass Spectrometry Methods".

\section{References}

1. K. Saarela, T. Tirkkonen, J. Laine-Ylijoki, J. Jurvelin, M. J.
Nieuwenhuijsen, and M. Jantunen, Atmos. Environ., 2003, 37, 5563.

2. Agency for Toxic Substances and Disease Registry (ATSDR), Toxicological Profile for Benzene, Atlanta, GA: U.S. Department of Health and Human Services, Public Health Service, http://www.atsdr.cdc.gov/toxprofiles/tp3. html.

3. United States Environmental Protection Agency (U.S EPA), Drinking Water Contaminants, http://www.epa.gov/ safewater/contaminants/index.html\#1.

4. Directive 98/83/EC of the Council of 3 November 1998, Official Journal of the European Communities 330, 05.12.1998, http://eurlex.europa.eu/LexUriServ/LexUriServ. do?uri=OJ:L:1998:330:0032:0054:EN:PDF.

5. S. D. Gregg, J. W. Fischer, and M. G. Bartlett, Biomed. Chromatogr., 2006, 20, 492.

6. A. Gaujac, E. S. Emídio, S. Navickiene, S. L. Ferreira, and H. S. Dórea, J. Chromatogr., A, 2008, 1203, 99.

7. E. Aguilera-Herrador, R. Lucena, S. Cárdenas, and M. Valcárcel, J. Chromatogr., A, 2008, 1201, 106.

8. M. Rosell, S. Lacorte, and D. Barceló, J. Chromatogr., A, 2006, 1132, 28.

9. H. C. Menezes, L. C. Amorim, and Z. L. Cardeal, Anal. Bioanal. Chem., 2009, 395, 2583.

10. A. Sarafraz-Yazdi, A. H. Amiri, and Z. Es'haghi, Talanta, 2009, 78, 936.

11. A. Sarafraz-Yazdi, A. H. Amiri, and Z. Es'haghi, Chemosphere, 2008, 71, 671 .

12. K. Farhadi, R. Maleki, and R. Tahmasebi, Anal. Lett., 2010, $43,349$.

13. R. A. Iglesias, F. Tsow, R. Wang, E. S. Forzani, and N. Tao, Anal. Chem., 2009, 81, 8930.

14. K. Beyer, D. Knopp, and R. Niessner, Food Technol. Biotechnol., 1997, 35, 215.

15. K. Beyer, D. Knopp, and R. Niessner, Vom Wasser, 1997 , 89, 37.

16. E. Francioni, G. Fillmann, C. Hamacher, Â. de Luca R. Wagener, M. H. Depledge, J. W. Readman, and M. de Fátima Guadalupe Meniconi, Environ. Technol., 2003, 24, 665.

17. S. Eremin, D. Knopp, R. Niessner, J. Hong, S. J. Park, and M. Choi, Environ. Chem., 2005, 3, 227.

18. S. Bi, Y. Yan, X. Yang, and S. Zhang, Chem. Eur. J., 2009, 15,4704

19. S. Girotti, E. Maiolini, S. Ghini, E. Ferri, F. Fini, P. Nodet, and S. Eremin, Anal. Lett., 2008, 41, 46.

20. United States Environmental Protection Agency (U.S EPA), Wastes-Hazardous Waste, http://www.epa.gov/waste/ hazard/testmethods/pdfs/5021a_r1.pdf.

21. United States Environmental Protection Agency (U.S EPA), Wastes-Hazardous Waste, http://www.epa.gov/osw/hazard/ testmethods/pdfs/8260c.pdf.

22. H. Towbin and O. Zingel, Anal. Biochem., 2007, 369, 256. 